\title{
The Southern European Atlantic Diet is associated with lower concentrations of markers of coronary risk
}

\author{
Pilar Guallar-Castillón ${ }^{\mathrm{a}, \mathrm{b}, *}$, Andreia Oliveira ${ }^{\mathrm{c}, \mathrm{d}}$, Carla Lopes ${ }^{\mathrm{c}, \mathrm{d}}$, Esther López-García ${ }^{\mathrm{a}, \mathrm{b}}$, \\ Fernando Rodríguez-Artalejo ${ }^{\mathrm{a}, \mathrm{b}}$ \\ ${ }^{a}$ Department of Preventive Medicine and Public Health, School of Medicine, Universidad Autónoma de Madrid/IdiPAZ, Madrid, Spain \\ ${ }^{\mathrm{b}}$ CIBER de Epidemiología y Salud Pública (CIBERESP), Madrid, Spain \\ ${ }^{\mathrm{c}}$ Departament of Clinical Epidemiology, Predictive Medicine and Public Health, Medical School, University of Porto, Porto, Portugal \\ ${ }^{\mathrm{d}}$ Public Health Institute, University of Porto, Porto, Portugal
}

\section{A R T I C L E I N F O}

\section{Article history:}

Received 5 October 2012

Received in revised form

27 November 2012

Accepted 30 November 2012

Available online 10 December 2012

\section{Keywords:}

Diet

Southern European Atlantic Diet

Coronary disease

Risk factors

Population-based studies

Spain

\begin{abstract}
A B S T R A C T
Objective: The Southern European Atlantic Diet (SEAD) is the traditional diet of Northern Portugal and Galicia, a region in northwest Spain. The SEAD has been associated with a lower risk of non-fatal acute myocardial infarction, but the mechanisms of this association have not yet been investigated. Thus, we examined the association between the SEAD and numerous biomarkers of coronary risk, blood pressure and anthropometrics.

Methods: Cross-sectional study conducted in 2008-2010 among 10,231 individuals representative of the population aged 18 years and older in Spain. Diet was assessed with a validated computerized diet history. SEAD adherence was measured with an index including 9 food components (fresh fish, cod, red meat and pork products, dairy products, legumes and vegetables, vegetable soup, potatoes, whole-grain bread, and wine), which ranges from 0 (lowest adherence) to 9 (highest adherence). C-reactive protein, uric acid, total cholesterol, LDL-cholesterol, HDL-cholesterol, triglycerides, glucose, glycated hemoglobin, insulin, leptin, fibrinogen, were determined in 12-h fasting blood samples, while creatinine and urine albumin were determined in urine.

Results: Mean SEAD score was 2.9 points (inter-quartile range $2-4$ points). Higher SEAD adherence was associated with a lower level of plasma C-reactive protein (adjusted difference in geometric means between the highest and lowest SEAD quartiles $-0.2 \mathrm{mg} / \mathrm{l} ; p$ for trend $<0.001$ ), plasma triglycerides $(-3.4 \mathrm{mg} / \mathrm{dl} ; p$ for trend 0.012$)$, insulin $(-0.5 \mathrm{mU} / \mathrm{l} ; p$ for trend $<0.001)$, HOMA-IR $(-0.12 ; p$ for trend $<0.001)$, urine albumin $(-0.8 \mathrm{mg} / \mathrm{l} ; p$ for trend $<0.001)$, urine albumin-creatinine ratio $(-0.3 \mathrm{mg} / \mathrm{g}$ creatinine; $p$ for trend $<0.034$ ), and systolic blood pressure $(-1.6 \mathrm{~mm} \mathrm{Hg}$; $p$ for trend $<0.001)$.

Conclusions: This study identifies possible mediators of the effect of SEAD on myocardial infarction, because SEAD is associated with a lower concentration of markers of inflammation and with reduced triglycerides, insulin, insulin resistance, and systolic blood pressure.
\end{abstract}

(c) 2012 Elsevier Ireland Ltd. All rights reserved.

\section{Introduction}

The Southern European Atlantic Diet (SEAD) is the traditional diet of northern Portugal and Galicia, a region in northwest Spain. The SEAD is characterized by high consumption of fish, red meat, dairy products, vegetables and legumes, soups, potatoes, wholewheat bread and wine [1,2]. Food recipes are simple, and boiling

\footnotetext{
* Corresponding author. Departamento de Medicina Preventiva y Salud Pública, Facultad de Medicina, Universidad Autónoma de Madrid, Avda. Arzobispo Morcillo, sn, 28029 Madrid, Spain. Tel.: +34 91 3475480; fax: +34 913475353.

E-mail address: mpilar.guallar@uam.es (P. Guallar-Castillón).
}

and steaming are the main culinary techniques. The SEAD differs from the traditional Mediterranean diet [3] in at least two important aspects. First, unlike the Mediterranean diet, the SEAD includes a high intake of red meat, pork, and fish. Second, olive oil is not the principal source of total fat in the SEAD, and nuts and fruit are not prominent components of the diet. However, like the Mediterranean diet, the SEAD is characterized by a high intake of vegetables and whole foods and by moderate wine consumption during meals.

Recently Oliveira et al. reported that higher adherence to the SEAD is associated with a lower risk of non-fatal acute myocardial infarction (AMI) [4]. Wine, legumes and vegetables, whole-grain bread, and dairy products were the food that contributed most to 
the reduced risk of AMI associated with the SEAD. However, the mechanisms of the association between the SEAD and AMI have not yet been investigated. Accordingly, this study examined the association between the SEAD and numerous biomarkers of coronary risk, blood pressure and anthropometry in a representative sample of the adult Spanish population.

\section{Methods}

\subsection{Study design and participants}

The data were taken from the Study on Nutrition and Cardiovascular Risk in Spain (ENRICA), whose methods have been reported elsewhere [5]. Briefly, this was a cross-sectional study conducted from June 2008 to October 2010 in 12,948 individuals aged 18 years and over, who were selected by stratified cluster sampling to achieve a representative sample of the noninstitutionalized Spanish population. The information on sociodemographic and lifestyle variables was collected by telephone interview. Two home visits were subsequently made. At the first visit, samples of blood and urine were obtained, and at the second visit a physical examination was conducted and dietary consumption was collected. The overall response rate was $51 \%$, which is among the highest in population surveys with health examination and collection of biological samples in Europe [6].

Study participants gave written consent. The study was approved by the Clinical Research Ethics Committee of the La Paz University Hospital, Madrid and the Clinic Hospital of Barcelona, Spain.

\subsection{Dietary assessment}

Information on diet was collected with a computerized dietary history developed from the one used in the EPIC-Spain cohort [79]. The dietary history allows collection of information on 900 foods and uses 127 sets of photographs to help quantify portion sizes. The dietary information refers to a typical week, and all foods consumed at least once every 15 days are recorded. Nutrient intake was then calculated using composition tables for Spanish and foreign foods [10-14].

\subsection{SEAD adherence}

To assess SEAD adherence we used an index that has been described elsewhere [4]. The SEAD index includes the following 9 key components: 1) Fresh fish excluding cod, 2) Cod, 3) Red meat and pork products, 4) Dairy products, 5) Legumes and vegetables, 6) Vegetable soup, 7) Potatoes, 8) Whole-grain bread, and 9) Wine. Each component (except wine) was measured as g/1000 kcal/day (to express intake as energy density). Consumption of each food (except wine) received a score of 1 if it was equal to or higher than the sexspecific median, and 0 if it was lower. For wine consumption, a score of 1 was assigned when it was $>0$ to $\leq 1$ glass/day in women and $>0$ to $\leq 2$ glasses/day in men. Higher or lower (i.e., none) wine consumption was scored as 0 . For each participant, the scores ( 0 or 1) for the 9 food components of the SEAD were summed; thus, the index ranged from 0 (lowest adherence to SEAD) to 9.

\subsection{Biomarkers of coronary risk, blood pressure and anthropometry}

Biomarkers of coronary risk were determined in 12-h fasting blood samples. Laboratory tests of blood and urine were made with the ADVIA 2400 Chemistry System Analyzer from Siemens in the Center of Biological Diagnostics of the Clínic Hospital in Barcelona, using standardized procedures and appropriate quality controls.
High-sensitivity C-reactive protein (hs-CRP) was measured by latex-enhanced nephelometry and uric acid by the uricaseperoxidase technique.

Total cholesterol was measured by an enzymatic method using cholesterol-esterase and cholesterol-oxidase. High-density lipoprotein cholesterol (HDL-c) was determined by the direct method, by elimination/catalase. Low-density lipoprotein cholesterol (LDLc) was calculated by the Friedewald formula [15]. Triglycerides were measured by the glycerol phosphate oxidase method.

Serum glucose was determined by the glucose oxidase method, glycated hemoglobin by high performance liquid chromatography (ADAMS A1c HA-8160 analyzer, Arkray), and insulin by immunoradiometric assay (IRMA). The index Homeostatic Model Assessment for Insulin Resistance (HOMA-IR) was calculated by multiplying glucose in $\mathrm{mg} / \mathrm{dl}$ by insulin in $\mathrm{mU} / \mathrm{l}$ and dividing by 405 [16].

Leptin was measured by enzyme-linked immunoassay (DBC, Diagnosis Biochem Canada, Inc) and fibrinogen by the coagulation method. Creatinine was determined by the Jaffé alkaline picrate kinetic reaction, and albumin in urine by PEG enhanced immunoturbidimetry.

Blood pressure was measured with validated automatic tensiometers (Omron model M6), using cuff sizes appropriate for arm circumference and following standardized procedures [17]. Two sets of measurements were made, and in each set blood pressure was measured three times 1-2 min apart, after the person had rested for at least $3-5 \mathrm{~min}$.

Weight, height, waist circumference and hip circumference were also measured under standardized conditions [18]. Calibrated electronic scales (Seca model 812, precision to $0.1 \mathrm{~kg}$ ), portable stadiometers (KaWe model 4444 Seca), and flexible measuring tapes with buckle were used for these measurements. Body mass index (BMI) was calculated by dividing weight in $\mathrm{kg}$ by height in $\mathrm{m}$ squared.

\subsection{Other variables}

Educational level was assessed by the highest academic level attained and was classified into three groups (primary, secondary and university). Leisure-time physical activity was measured using a validated questionnaire [19] and was expressed in metabolic equivalent units (METs)-h/week [20]. Respondents were also asked about their smoking habits. Former smokers were defined as those individuals who reported not to smoke but to have done it in the past. Among current smokers, the number of cigarettes smoked per day was registered. Finally, individuals reported whether they had been diagnosed by a physician with any of the following diseases: acute myocardial infarction, stroke, heart failure, or cancer at any site.

Adherence to the Mediterranean diet was assessed with the index of Trichopoulou et al. [21,22] For the characteristic components of this diet (vegetables, legumes, fruits and nuts, cereals, fish, ratio of monounsaturated fatty acids to saturated fatty acids), consumption below the sex-specific median received a score of 0 , and equal or greater consumption was scored as 1 . Inverse scores were used for components not characteristic of the Mediterranean diet (meat, white meat, and dairy products). For alcohol intake, a score of 1 was assigned to men who consumed $10-50 \mathrm{~g} / \mathrm{d}$ and to women who consumed 5-25 g/d. Accordingly, the Mediterranean diet index ranged from 0 (lowest adherence) to 9 .

\subsection{Statistical analysis}

Of the initial sample of 12,948 individuals, 12,042 provided information on diet. Of these, 60 were excluded due to extreme 
energy intake $(<800 \mathrm{kcal} / \mathrm{d}$ or $>5000 \mathrm{kcal} / \mathrm{d}$ in men; $<500 \mathrm{kcal} / \mathrm{d}$ or $>4000 \mathrm{kcal} / \mathrm{d}$ in women) [23] and 724 were excluded for lack of information on physical activity, smoking or BMI. We also excluded 252 participants with cardiovascular disease (myocardial infarction, stroke or heart failure), 104 with cancer, and 668 with diabetes (fasting serum glucose $\geq 126 \mathrm{mg} / \mathrm{dl}$ or in treatment with oral antidiabetic agents or insulin). Thus, the main analyses were conducted with 10,231 individuals. In analyses using hs-CRP, we excluded 10 individuals with hs-CRP $>10 \mathrm{mg} / \mathrm{l}$ because this level may result from an acute clinical episode. In analyses using LDLcholesterol, we also excluded 4 individuals with triglycerides $>400 \mathrm{mg} / \mathrm{dl}$ because in these cases the Friedewald formula is not appropriate.

To assess the study associations we used generalized linear models, where biomarkers of coronary risk or blood pressure or anthropometrics were the dependent variable, and the SEAD score was the main independent variable. Several biomarkers did not follow a normal distribution according to the KolmogorovSmirnov test. Thus, we used log-transformed plasma and urine concentrations of biomarkers to achieve normal distributions. The SEAD score was modeled in quartiles by using dummy terms. Analyses were adjusted for sex, age, METS-h/week of physical activity and BMI (as continuous variables), education (primary, secondary, university), tobacco smoking (never, former, current smoker of 1-14 cigarettes/d, current-smoker of $\geq 15$ cigarettes/d), and alcohol intake $(<1,1-4.9,5.0-9.9, \geq 10 \mathrm{~g} / \mathrm{d})$. The main results are presented as the adjusted mean difference, and $95 \%$ confidence interval $(\mathrm{CI})$, in biomarkers, blood pressure and anthropometrics between the highest and lowest quartile of the SEAD score. To test for linear trend, the SEAD score was modeled as a continuous variable. Lastly, to assess whether results varied with sex, we tested interactions using a factorial analysis of variance.

Sensitivity analyses were performed to observe the influence of adjusting for energy intake and for consumption of other commonly eaten foods not included in the SEAD index, such as white meat, fruit and refined cereals. Furthermore, the analyses were repeated without adjusting for either BMI or alcohol consumption, as these could act as mediators of the study associations.

Statistical significance was set at $p<0.05$ (two tailed). Analyses were performed with SAS System version 9.2 for Windows (SAS Institute, Cary, NC).

\section{Results}

The mean SEAD score was 2.9 points (inter-quartile range $2-4$ points). Adherence to the SEAD varied considerably in the study sample, with the score ranging from $<1$ points in the lowest quartile to $\geq 4$ points in the highest quartile. The composition of the SEAD in this study was comparable to that in Northern Portugal, where the previous study on SEAD was conducted, except for consumption of cod and vegetable soup, which was low in Spain but fairly high in Portugal. ${ }^{4}$ Consumption of each of the 9 food components of the SEAD increased with increasing quartiles of the SEAD score (Table 1). A higher SEAD score was also associated with small, but statistically significant, changes in the intake of many nutrients. However, as expected, a substantial change was observed for protein, omega-3 fatty acids from fish, fiber, calcium and folate, whose intake increased across increasing quartiles of SEAD adherence (Table 1 ).

Individuals with greater SEAD adherence were more frequently men, older and more educated, did more leisure-time physical activity, had a higher alcohol intake, and were less frequently current smokers (Table 2).

In multivariable analyses, a greater adherence to the SEAD was associated with a lower level of plasma hs-CRP (adjusted difference in geometric means between the highest and lowest SEAD quartiles $-0.20 \mathrm{mg} / \mathrm{l} ; p$ for trend $<0.001)$, plasma triglycerides $(-3.39 \mathrm{mg} / \mathrm{dl}$;

Table 1

Food and nutrient intake according to quartiles of the SEAD score in the adult Spanish population from the ENRICA study. $N=10,231$.

\begin{tabular}{|c|c|c|c|c|c|}
\hline & \multicolumn{4}{|c|}{ Quartile of SEAD score } & \multirow{3}{*}{$\frac{p \text { for trend }}{<0.0001}$} \\
\hline & 1 Mean (SD) & 2 Mean (SD) & 3 Mean (SD) & 4 Mean (SD) & \\
\hline & $0.8(0.4)$ & $2.0(0)$ & $3(0)$ & $4.5(0.7)$ & \\
\hline \multicolumn{6}{|l|}{ Components of the SEAD score $(\mathrm{g} / 1000 \mathrm{kcal} / \mathrm{d})$} \\
\hline Fresh fish & $12.1(12.3)$ & $16.2(16.3)$ & $24.0(19.8)$ & $32.8(21.6)$ & $<0.0001$ \\
\hline Cod & $0.1(0.7)$ & $0.2(1.3)$ & $0.5(2.5)$ & $1.3(3.4)$ & $<0.0001$ \\
\hline Red meat and pork products & $36.2(26.2)$ & $42.0(28.3)$ & $41.9(27.4)$ & $46.3(25.3)$ & $<0.0001$ \\
\hline Dairy products & $106.1(75.2)$ & $126.8(83.7)$ & $150.3(99.0)$ & $168.9(95.2)$ & $<0.0001$ \\
\hline Legumes and vegetables & $74.8(64.0)$ & $106.6(76.9)$ & $136.3(85.2)$ & $154.1(81.7)$ & $<0.0001$ \\
\hline Vegetable soup & $0.2(1.6)$ & $0.6(3.7)$ & $1.5(8.0)$ & $4.9(17.9)$ & $<0.0001$ \\
\hline Potatoes & $16.2(11.5)$ & $19.7(15.0)$ & $22.2(17.7)$ & $28.0(20.0)$ & $<0.0001$ \\
\hline Whole-grain bread & $0.7(7.8)$ & $3.5(18.7)$ & $5.7(19.8)$ & $12.1(25.5)$ & $<0.0001$ \\
\hline Wine & $15.3(62.6)$ & $18.9(60.2)$ & $20.8(48.0)$ & $26.7(45.2)$ & $<0.0001$ \\
\hline Energy (kcal/d) & $2414.6(708.6)$ & $2270.1(622.4)$ & $2136.5(619.9)$ & $2020.6(571.9)$ & \\
\hline \multicolumn{6}{|l|}{ Nutrients } \\
\hline Protein (\% of energy) & $15.7(2.9)$ & $17.1(3.1)$ & $18.3(3.5)$ & $19.8(3.7)$ & $<0.0001$ \\
\hline Saturated fat (\% of energy) & $12.7(3.9)$ & $12.2(3.4)$ & $11.6(3.2)$ & $11.1(2.8)$ & $<0.0001$ \\
\hline Monounsaturated fat (\% of energy) & $15.3(3.7)$ & $15.8(3.5)$ & $15.9(3.4)$ & $15.8(3.4)$ & $<0.0001$ \\
\hline Linoleic acid (\% of energy) & $5.5(2.2)$ & $5.4(2.1)$ & $5.3(2.0)$ & $5.1(1.8)$ & $<0.0001$ \\
\hline Alfa-linolenic acid (\% of energy) & $0.4(0.2)$ & $0.4(0.2)$ & $0.5(0.2)$ & $0.5(0.2)$ & $<0.0001$ \\
\hline Omega-3 fatty acids from fish (\% of energy) & $0.2(0.2)$ & $0.3(0.3)$ & $0.4(0.4)$ & $0.5(0.4)$ & $<0.0001$ \\
\hline Trans fat (\% of energy) & $1.0(0.6)$ & $1.0(0.6)$ & $0.9(0.5)$ & $0.8(0.5)$ & $<0.0001$ \\
\hline Cholesterol (mg/d) & $167.9(69.9)$ & $158.9(57.2)$ & $158.2(53.8)$ & $164.9(50.3)$ & 0.861 \\
\hline Sugars (\% of energy) & $17.7(7.5)$ & $17.4(6.4)$ & $18.0(6.2)$ & $18.2(5.6)$ & 0.007 \\
\hline Polysaccharides (\% of energy) & $26.6(7.4)$ & $25.3(6.8)$ & $24.0(6.4)$ & $22.8(5.8)$ & $<0.0001$ \\
\hline Total carbohydrates (\% of energy) & $44.3(8.1)$ & $42.7(7.4)$ & $42.0(7.1)$ & $41.0(6.6)$ & $<0.0001$ \\
\hline Ethanol (\% of energy) & $2.5(5.4)$ & $2.6(5.0)$ & $2.6(4.3)$ & $2.7(3.6)$ & 0.183 \\
\hline Fiber $(\mathrm{g} / \mathrm{d})$ & $9.3(3.2)$ & $10.2(3.5)$ & $11.3(3.8)$ & $11.9(3.6)$ & $<0.0001$ \\
\hline Calcium (mg/d) & $356.2(126.4)$ & $392.0(142.5)$ & $427.5(157.1)$ & $452.3(142.5)$ & $<0.0001$ \\
\hline Sodium (mg/d) & $1341.2(423.8)$ & $1419.9(498.0)$ & $1385.8(389.3)$ & $1374.5(387.6)$ & 0.555 \\
\hline Folate $(\mu \mathrm{g} / \mathrm{d})$ & $116.4(45.2)$ & $136.3(48.5)$ & $156.2(56.2)$ & $167.0(52.3)$ & $<0.0001$ \\
\hline
\end{tabular}

Quartile values of SEAD score: quartile 1 (lowest adherence), $\leq 1$ point; quartile 2, 2 points; quartile 3,3 points; quartile 4 (highest adherence), $\geq 4$ points. 
Table 2

Characteristics of study participants according to quartiles of the SEAD score in the adult Spanish population from the ENRICA study. $N=10,231$.

\begin{tabular}{|c|c|c|c|c|c|}
\hline & \multicolumn{4}{|c|}{ Quartile of SEAD score } & \multirow[t]{2}{*}{$p$ for trenc } \\
\hline & 1 & 2 & 3 & 4 & \\
\hline$n(\%)$ & $1550(15.15)$ & $2647(25.88)$ & $2904(28.38)$ & $3130(30.60)$ & \\
\hline Males, \% & 44.1 & 49.8 & 47.3 & 50.4 & $<0.0001$ \\
\hline Age (years), mean (SD) & $40.1(16.6)$ & $42.4(15.9)$ & $46.8(16.3)$ & $49.6(15.5)$ & $<0.0001$ \\
\hline Education, \% & & & & & $<0.0001$ \\
\hline Primary & 27.2 & 26.5 & 28.6 & 29.1 & \\
\hline Secondary & 48.5 & 45.7 & 41.7 & 39.8 & \\
\hline University & 24.4 & 27.7 & 29.7 & 31.1 & \\
\hline Physical activity (MET-h/week), mean (SD) & $27.8(23.6)$ & $28.7(23.0)$ & $28.7(21.7)$ & $29.8(23.2)$ & 0.004 \\
\hline Smoking status, \% & & & & & $<0.0001$ \\
\hline Never & 48.6 & 49.6 & 48.7 & 51.8 & \\
\hline Former & 19.8 & 21.4 & 26.7 & 28.1 & \\
\hline Current $<14 \mathrm{cig} / \mathrm{d}$ & 14.5 & 13.6 & 12.6 & 11.8 & \\
\hline Current $\geq 15 \mathrm{cig} / \mathrm{d}$ & 17.2 & 15.4 & 12.0 & 9.3 & \\
\hline Alcohol intake (g/d), \% & & & & & $<0.0001$ \\
\hline$<1$ & 59.9 & 53.8 & 49.7 & 39.9 & \\
\hline $1-4.9$ & 8.4 & 11.1 & 11.6 & 16.8 & \\
\hline $5.0-10.0$ & 8.2 & 8.4 & 9.4 & 11.7 & \\
\hline$>10.0$ & 23.6 & 26.8 & 29.3 & 31.7 & \\
\hline
\end{tabular}

Quartiles of SEAD score as in Table 1.

$p$ for trend 0.012$)$, insulin $(-0.50 \mathrm{mU} / \mathrm{l} ; p$ for trend $<0.001)$, HOMAIR $(-0.12 ; p$ for trend $<0.001)$, urine albumin $(-0.84 \mathrm{mg} / \mathrm{l} ; p$ for trend $<0.001)$, urine albumin-creatinine ratio $(-0.30 \mathrm{mg} / \mathrm{g}$ creatinine; $p$ for trend 0.034$)$ and systolic blood pressure $(-1.55 \mathrm{~mm} \mathrm{Hg}$; $p$ for trend $<0.001$ ) (Table 3 ). The results for systolic blood pressure also hold when we excluded the 1279 individuals under antihypertensive drug treatment $(-1.54 \mathrm{~mm} \mathrm{Hg} ; p$ for trend $=0.002)$. The results were similar when the analyses were repeated without adjustment for alcohol intake (wine intake is a component of the SEAD) and BMI (a possible mediator in the pathway from SEAD to coronary risk biomarkers and blood pressure). Moreover, the results did not materially change after controlling for energy intake, and for consumption of white meat, fruit and refined cereals (data not shown). Results were also similar in men and women, except for insulin and HOMA-IR that reached statistical significance only among women ( $p$ for interaction $<0,0001$ ) (Online Supplement Tables 1 and 2).

Since the consumption of cod and vegetable was low, we replicated the analyses using a SEAD score which excluded these two food items. Results were similar to those using the full SEAD

Table 3

Plasma and urine concentrations of coronary risk biomarkers, blood pressure and anthropometrics according to quartiles of the SEAD score. ${ }^{\mathrm{a}}$

\begin{tabular}{|c|c|c|c|c|c|c|}
\hline & \multirow[t]{2}{*}{$N$} & \multicolumn{4}{|l|}{ Quartile of SEAD score } & \multirow[t]{2}{*}{$p$ for trend } \\
\hline & & 1 Mean $(95 \% \mathrm{CI})$ & 2 Mean $(95 \% \mathrm{CI})$ & 3 Mean $(95 \% \mathrm{CI})$ & 4 Mean $(95 \% \mathrm{CI})$ & \\
\hline \multicolumn{7}{|l|}{ Biomarkers } \\
\hline Hs-CRP (mg/l) $)^{\mathrm{b}, \mathrm{c}}$ & 10177 & $1.46(1.37-1.55)$ & $1.36(1.30-1.42)$ & $1.29(1.24-1.35)$ & $1.26(1.21-1.31)$ & $<0.001$ \\
\hline Uric acid $(\mathrm{mg} / \mathrm{dl})^{\mathrm{c}}$ & 10189 & $5.02(4.96-5.06)$ & $5.02(4.98-5.06)$ & $5.00(4.96-5.04)$ & $5.06(5.02-5.10)$ & 0.077 \\
\hline Total cholesterol $(\mathrm{mg} / \mathrm{dl})^{\mathrm{c}}$ & 10185 & $192.45(190.71-194.21)$ & $192.79(191.46-194.12)$ & $194.15(192.89-195.42)$ & $194.32(193.09-195.57)$ & 0.105 \\
\hline LDL-cholesterol $(\mathrm{mg} / \mathrm{dl})^{\mathrm{c}}$ & 10089 & $116.35(114.88-117.84)$ & $117.62(116.49-118.76)$ & $118.16(117.09-119.24)$ & $118.46(117.41-119.53)$ & 0.074 \\
\hline HDL-cholesterol $(\mathrm{mg} / \mathrm{dl})^{\mathrm{c}}$ & 10185 & $51.98(51.41-52.55)$ & $51.79(51.36-52.22)$ & $52.40(51.99-52.97)$ & $52.22(51.82-52.63)$ & 0.148 \\
\hline Total cholesterol/HDL-cholesterol & 10185 & $3.83(3.78-3.88)$ & $3.86(3.82-3.90)$ & $3.84(3.81-3.88)$ & $3.86(3.83-3.90)$ & 0.714 \\
\hline LDL-cholesterol/HDL-cholesterol & 10089 & $2.36(2.33-2.40)$ & $2.41(2.38-2.44)$ & $2.39(2.37-2.42)$ & $2.41(2.38-2.43)$ & 0.344 \\
\hline Triglycerides $(\mathrm{mg} / \mathrm{dl})^{\mathrm{c}}$ & 10185 & $96.92(94.76-99.14)$ & $93.59(92.00-95.21)$ & $93.66(92.16-95.19)$ & $93.53(92.06-95.03)$ & 0.012 \\
\hline Glucose $(\mathrm{mg} / \mathrm{dl})^{\mathrm{c}}$ & 10103 & $89.32(88.76-89.89)$ & $88.76(88.33-89.18)$ & $89.02(88.62-89.42)$ & $88.50(88.11-88.86)$ & 0.071 \\
\hline Glycated hemoglobin (\%) ${ }^{\mathrm{c}}$ & 10144 & $4.64(4.63-4.66)$ & $4.63(4.62-4.65)$ & $4.64(4.63-4.65)$ & $4.63(4.62-4.65)$ & 0.820 \\
\hline Insulin $(\mathrm{mU} / \mathrm{l})^{\mathrm{c}}$ & 10179 & $7.55(7.34-7.77)$ & $7.62(7.46-7.79)$ & $7.39(7.23-7.54)$ & $7.05(6.91-7.20)$ & $<0.001$ \\
\hline HOMA-IR & 10093 & $1.67(1.61-1.72)$ & $1.68(1.64-1.72)$ & $1.63(1.60-1.67)$ & $1.55(1.51-1.58)$ & $<0.001$ \\
\hline Leptin $(\mathrm{ng} / \mathrm{ml})^{\mathrm{c}}$ & 10182 & $12.33(11.92-12.75)$ & $12.31(12.00-12.63)$ & $12.43(12.14-12.73)$ & $12.02(11.74-12.31)$ & 0.469 \\
\hline Fibrinogen $(g / l)^{c}$ & 10073 & $3.32(3.29-3.35)$ & $3.32(3.30-3.34)$ & $3.31(3.29-3.33)$ & $3.30(3.28-3.32)$ & 0.305 \\
\hline Creatinine $(\mathrm{mg} / \mathrm{dl})^{\mathrm{c}}$ & 10187 & $0.84(0.84-0.85)$ & $0.84(0.84-0.85)$ & $0.84(0.84-0.85)$ & $0.85(0.84-0.85)$ & 0.159 \\
\hline Urine albumin $(\mathrm{mg} / \mathrm{l})^{\mathrm{c}}$ & 10144 & $6.69(6.38-7.01)$ & $6.49(6.26-6.73)$ & $6.18(5.96-6.40)$ & $5.85(5.66-6.05)$ & $<0.001$ \\
\hline $\begin{array}{l}\text { Urine albumin-creatinine ratio } \\
(\mathrm{mg} / \mathrm{g} \text { creatinine })^{\mathrm{c}}\end{array}$ & 10142 & $5.21(5.00-5.44)$ & $5.06(4.90-5.23)$ & $5.12(4.97-5.28)$ & $4.91(4.77-5.06)$ & 0.034 \\
\hline \multicolumn{7}{|l|}{ Blood pressure } \\
\hline Systolic blood pressure (mm Hg) & 10149 & $128.20(127.48-128.92)$ & $127.44(126.90-127.99)$ & $127.73(127.22-128.24)$ & $126.65(126.14-127.15)$ & $<0.001$ \\
\hline Diastolic blood pressure ( $\mathrm{mm} \mathrm{Hg}$ ) & 10149 & $75.53(75.07-75.99)$ & $75.41(75.07-75.76)$ & $75.63(75.29-75.96)$ & $75.47(75.16-75.80)$ & 0.817 \\
\hline \multicolumn{7}{|l|}{ Anthropometrics } \\
\hline Body mass index $\left(\mathrm{kg} / \mathrm{m}^{2}\right)$ & 10231 & $26.43(26.21-26.64)$ & $26.63(26.47-26.80)$ & $26.65(26.49-26.80)$ & $26.70(26.55-26.85)$ & 0.083 \\
\hline Waist circumference $(\mathrm{cm})$ & 10208 & $89.86(89.55-90.17)$ & $89.57(89.34-89.81)$ & $89.42(89.20-89.64)$ & $89.47(89.25-89.69)$ & 0.117 \\
\hline Waist-to-hip ratio & 10202 & $0.871(0.868-0.874)$ & $0.869(0.866-0.872)$ & $0.877(0.865-0.870)$ & $0.868(0.866-0.870)$ & 0.216 \\
\hline
\end{tabular}

CI: Confidence interval. Quartiles of SEAD as in Table 1.

a Values are adjusted for sex, age, education (primary, secondary, university), MET-h/week of physical activity, smoking status (never, former, current 1-14 cig/d, current $\geq 15 \mathrm{cig} / \mathrm{d})$, alcohol intake ( $<1,1-4.9,5.0-9.9, \geq 10.0 \mathrm{~g} / \mathrm{d})$ and BMI.

b Individuals with C-reactive protein $\geq 10 \mathrm{mg} / \mathrm{l}$ were excluded.

c Geometric mean. 
score. Specifically, the adjusted difference in geometric means between the extremes SEAD quartiles were $-0.18 \mathrm{mg} / \mathrm{l}$ ( $p$ for trend $<0.001$ ) for hs-CRP, $-4.1 \mathrm{mg} / \mathrm{dl}$ ( $p$ for trend 0.003 ) for triglycerides, $-0.60 \mathrm{mU} / \mathrm{l}$ ( $p$ for trend $<0.001$ ) for insulin, -0.14 ( $p$ for trend $<0.001$ ) for HOMA-IR, $-0.7 \mathrm{mg} / \mathrm{l}$ ( $p$ for trend $<0.001$ ) for urine albumin, $-0.20 \mathrm{mg} / \mathrm{g}$ creatinine ( $p$ for trend $<0.467$ ) for the urine albumin-creatinine ratio, and $-1.8 \mathrm{~mm} \mathrm{Hg}(p$ for trend $<0.001)$ for systolic blood pressure.

In secondary analyses, we aimed to identify individual food components of the SEAD which could contribute to the association between SEAD and lower biomarkers of coronary risk. Fish, legume and vegetable consumption were associated with statistically significant lower levels of plasma hs-CRP, and fish consumption was related to reduced plasma triglycerides. Lastly, cod, legume and vegetable consumption were linked to lower urine albumin, urine albumin-creatinine ratio and systolic blood pressure (data not shown).

Finally, to place the association between the SEAD and coronary risk into the context of what can be expected from a healthy diet, we calculated the Mediterranean diet index, and replicated the analyses replacing the SEAD score with the Mediterranean diet score. Hs-CRP, urine albumin, insulin and systolic blood pressure decreased with increasing adherence to the Mediterranean diet; furthermore, the difference in the values of these variables between the highest and lowest quartiles of the Mediterranean diet $(-0.15 \mathrm{mg} / \mathrm{dl}$ for hs-CRP, $-0.46 \mathrm{mU} / \mathrm{l}$ for insulin, -0.10 for HOMAIR, $-0.77 \mathrm{mg} / \mathrm{l}$ for urine albumin, $-0.27 \mathrm{mg} / \mathrm{g}$ for the albumin/ creatinine ratio, and $-1.28 \mathrm{~mm} \mathrm{Hg}$ in systolic blood pressure) was similar to that observed for the SEAD (Table 4). However, no association was observed for triglycerides, although there was a reduction in creatinine and BMI with increasing adherence to the Mediterranean diet. Lastly, the results were similar in men and women, except for CRP ( $p$ for interaction $=0.007$ ) and HOMA-IR ( $p$ for interaction $=0.035$ ) that reached significance only among women (Online Supplement Tables 3 and 4).

\section{Discussion}

Our results show that higher SEAD adherence is associated with lower concentrations of hs-CRP, triglycerides and insulin, lower insulin resistance, and lower urine albumin and systolic blood pressure. Accordingly, they identify possible intermediate variables in the association between SEAD and lower risk of non-fatal AMI.

Adherence to the SEAD among the study participants was moderate, once we account for the fact that SEAD has been defined as a "traditional" dietary pattern. Thus, certain deviations from this pattern can be expected because of changes in lifestyles related to socioeconomic development, the progressive incorporation of women to paid job, and the relative changes in the price of the food components of SEAD over time. Nevertheless, Table 1 showed that consumption of all food components of the SEAD was fairly high with the exception of cod and vegetable soup, but it was compensated by a substantial consumption of fresh fish and legumes and vegetables.

Atheromatosis is an inflammatory disease [24]. CRP is a marker of inflammation and, although its specific function is not well known, it appears to exacerbate tissue damage in individuals with a substantial volume of damaged tissue [25]. Numerous prospective studies have shown a modest association between CRP and the risk of ischemic heart disease and other forms of cardiovascular disease $[26,27]$. However, a recent Mendelian randomization analysis including 200,000 subjects did not find that CRP was associated with other cardiovascular risk factors or with coronary heart disease (CHD) [28]. Thus, the causal role of CRP in CHD has been

Table 4

Plasma and urine concentrations of coronary risk biomarkers, blood pressure and anthropometrics according to quartiles of the Mediterranean diet score ${ }^{\mathrm{a}}$.

\begin{tabular}{|c|c|c|c|c|c|c|}
\hline & \multirow[t]{2}{*}{$N$} & \multicolumn{4}{|c|}{ Quartile of Mediterranean diet score } & \multirow[t]{2}{*}{$p$ for trend } \\
\hline & & 1 Mean $(95 \% \mathrm{CI})$ & 2 Mean $(95 \% \mathrm{CI})$ & 3 Mean $(95 \% \mathrm{CI})$ & 4 Mean $(95 \% \mathrm{CI})$ & \\
\hline \multicolumn{7}{|l|}{ Biomarkers } \\
\hline Hs-CRP (mg/l) & 10177 & $1.41(1.35-1.46)$ & $1.26(1.20-1.33)$ & $1.31(1.25-1.38)$ & $1.26(1.20-1.33)$ & $<0.001$ \\
\hline Uric acid $(\mathrm{mg} / \mathrm{dl})^{\mathrm{c}}$ & 10189 & $4.99(4.96-5.03)$ & $5.00(4.95-5.04)$ & $5.09(5.04-5.14)$ & $5.05(5.01-5.09)$ & $<0.001$ \\
\hline Total cholesterol $(\mathrm{mg} / \mathrm{dl})^{\mathrm{c}}$ & 10185 & $192.45(191.30-193.60)$ & $194.24(192.76-195.72)$ & $194.43(192.93-195.94)$ & $194.08(192.65-195.53)$ & 0.048 \\
\hline LDL-cholesterol (mg/dl $)^{c}$ & 10089 & $116.97(116.00-117.95)$ & $118.55(117.28-119.84)$ & $118.09(116.87-119.32)$ & $118.09(116.87-119.32)$ & 0.131 \\
\hline HDL-cholesterol $(\mathrm{mg} / \mathrm{dl})^{\mathrm{c}}$ & 10185 & $51.66(51.29-52.03)$ & $52.10(51.62-52.58)$ & $52.82(52.33-53.32)$ & $52.26(51.79-52.73)$ & 0.010 \\
\hline Total cholesterol/HDL-cholesterol & 10185 & $3.86(3.83-3.89)$ & $3.87(3.83-3.91)$ & $3.82(3.78-3.86)$ & $3.85(3.82-3.89)$ & 0.532 \\
\hline LDL-cholesterol/HDL-cholesterol & 10089 & $2.40(2.37-2.42)$ & $2.40(2.37-2.44)$ & $2.38(2.35-2.41)$ & $2.40(2.37-2.43)$ & 0.962 \\
\hline Triglycerides $(\mathrm{mg} / \mathrm{dl})^{\mathrm{c}}$ & 10185 & $95.18(93.78-96.60)$ & $94.74(92.96-96.55)$ & $92.19(90.44-93.98)$ & $93.52(91.80-95.26)$ & 0.104 \\
\hline Glucose $(\mathrm{mg} / \mathrm{dl})^{\mathrm{c}}$ & 10103 & $88.51(88.14-88.87)$ & $8.86(88.39-89.33)$ & $89.38(88.90-89.86)$ & $88.85(88.39-89.31)$ & 0.063 \\
\hline Glycated hemoglobin (\%) ${ }^{\mathrm{c}}$ & 10144 & $4.63(4.62-4.64)$ & $4.64(4.62-4.65)$ & $4.65(4.63-4.66)$ & $4.64(4.62-4.65)$ & 0.258 \\
\hline Insulin $(\mathrm{mU} / \mathrm{l})^{\mathrm{c}}$ & 10179 & $7.60(7.46-7.74)$ & $7.30(7.13-7.48)$ & $7.28(7.11-7.46)$ & $7.14(6.98-7.32)$ & $<0.001$ \\
\hline HOMA-IR & 10093 & $1.67(1.63-1.70)$ & $1.61(1.57-1.65)$ & $1.61(1.57-1.65)$ & $1.57(1.54-1.61)$ & $<0.001$ \\
\hline Leptin $(\mathrm{ng} / \mathrm{ml})^{\mathrm{c}}$ & 10182 & $12.47(12.20-12.75)$ & $12.00(11.67-12.34)$ & $12.36(12.02-12.72)$ & $12.08(11.75-12.41)$ & 0.122 \\
\hline Fibrinogen $(g / l)^{c}$ & 10073 & $3.32(3.30-3.34)$ & $3.33(3.30-3.36)$ & $3.30(3.27-3.32)$ & $3.30(3.27-3.32)$ & 0.270 \\
\hline Creatinine $(\mathrm{mg} / \mathrm{dl})^{\mathrm{c}}$ & 10187 & $0.85(0.84-0.85)$ & $0.84(0.84-0.85)$ & $0.85(0.84-0.85)$ & $0.84(0.83-0.84)$ & 0.022 \\
\hline Urine albumin $(\mathrm{mg} / \mathrm{l})^{\mathrm{c}}$ & 10144 & $6.58(6.37-6.78)$ & $6.30(6.06-6.56)$ & $6.06(5.82-6.32)$ & $5.81(5.59-6.04)$ & $<0.001$ \\
\hline $\begin{array}{l}\text { Urine albumin-creatinine ratio } \\
\quad(\mathrm{mg} / \mathrm{g} \text { creatinine })^{\mathrm{c}}\end{array}$ & 10142 & $5.19(5.04-5.33)$ & $5.14(4.96-5.32)$ & $5.05(4.87-5.23)$ & $4.92(6.98-7.32)$ & $<0.001$ \\
\hline \multicolumn{7}{|l|}{ Blood pressure } \\
\hline Systolic blood pressure (mm Hg) & 10149 & $127.92(127.45-128.39)$ & $127.44(126.84-128.04)$ & $127.28(126.66-127.89)$ & $126.64(126.05-127.22)$ & 0.007 \\
\hline Diastolic blood pressure (mm Hg) & 10149 & $75.40(75.09-75.70)$ & $75.75(75.36-76.13)$ & $75.76(75.36-76.15)$ & $75.26(74.88-75.64)$ & 0.621 \\
\hline \multicolumn{7}{|l|}{ Anthropometrics } \\
\hline Body mass index $\left(\mathrm{kg} / \mathrm{m}^{2}\right)$ & 10231 & $26.87(26.73-27.01)$ & $26.76(26.58-26.95)$ & $26.45(26.27-26.63)$ & $26.28(26.10-26.45)$ & $<0.001$ \\
\hline Waist circumference $(\mathrm{cm})$ & 10208 & $89.47(89.27-89.68)$ & $89.70(89.45-89.96)$ & $89.60(89.33-89.86)$ & $89.46(89.20-89.71)$ & 0.934 \\
\hline Waist-to-hip ratio & 10202 & $0.867(0.865-870)$ & $0.870(0.867-873)$ & $0.869(0.867-0.872)$ & $0.868(0.865-870)$ & 0.256 \\
\hline
\end{tabular}

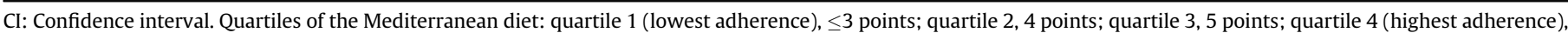
$\geq 6$ points.

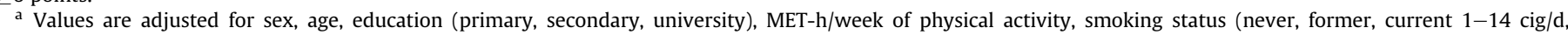
current $>15 \mathrm{cig} / \mathrm{d})$, alcohol intake $(<1,1-4.9,5.0-9.9, \geq 10.0 \mathrm{~g} / \mathrm{d})$ and BMI.

$\mathrm{b}$ Individuals with C-reactive protein $\geq 10 \mathrm{mg} / \mathrm{l}$ were excluded.

c Geometric means. 
questioned. Nonetheless, statin treatment has shown a reduction in cardiovascular events among patients without hypercholesterolemia but with elevated CRP; furthermore, the reduced coronary risk was associated with the reduction in CRP with statins [29].

Regardless of the specific role of CRP in the pathogenesis of CHD, the lower concentration of CRP associated with the SEAD suggests that this dietary pattern may reduce CHD by means of an antiinflammatory mechanism. Other heart-healthy dietary patterns, like the Prudent pattern, resulting from a factorial analysis in the Nurses' Health Study I [30], or the Mediterranean diet [31] have been associated with lower CRP concentrations. Like these dietary patterns, the SEAD is rich in folate and vitamin $C$ from vegetables, and in omega-3 fatty acids from fish, which have also been associated with lower hs-CRP [32].

In our study, the reduction of CRP between extreme quartiles of the SEAD score was modest $(-0.2 \mathrm{mg} / \mathrm{l})$. This reduction was similar to that observed in quintiles of the Prudent diet in the Nurses' Health Study I [30], and somewhat less than that observed in a clinical trial with the Mediterranean diet supplemented with olive oil in comparison to a low-fat diet $(-0.54 \mathrm{mg} / \mathrm{l})$ [31]. However, it should be noted that in a meta-analysis of observational studies, a three-fold higher than usual CRP concentration was associated with a 36\% excess risk of CHD [26]. Thus the reduction in CRP could make only a small contribution to the reduced risk of AMI associated with the SEAD.

There is increasing evidence that elevated triglycerides are not only a marker of cardiovascular risk but also a risk factor independent of HDL-c and LDL-c [33,34]. In our study we observed a difference of $-3.4 \mathrm{mg} / \mathrm{dl}$ between the quartiles of highest and lowest adherence to the SEAD. Therefore, the effect of the SEAD on triglycerides is small, although it is similar to what is achieved by losing $2 \mathrm{~kg}$ [35]. The Mediterranean diet [36] and the OmniHeart diet [37], which like the SEAD are rich in fiber, protein and unsaturated fat, also slightly reduce triglycerides. Furthermore, there is evidence that the omega- 3 fatty acids from fish, which are rich in the SEAD, reduce triglycerides [38]. In our analyses we have seen that fish consumption increased greatly with increasing quartiles of the SEAD score, and that fish consumption was associated with a lower triglyceride level.

In our study, serum insulin decreased with increasing adherence to the SEAD. In a subsample of 466 men from the Health Professionals Follow-up Study, the investigators also observed a negative correlation between adherence to the Prudent dietary pattern and the serum insulin level [39]. In the same way, prolonged adherence to a Mediterranean-style diet is accompanied by reduced insulin and improved insulin sensitivity [40]. Furthermore, various components of the SEAD like consumption of whole grains and intake of omega- 3 fatty acids from fish have also been associated with reduced insulin $[41,42]$

There is evidence from population-based studies that albuminuria is an independent risk factor for CHD. Moreover, the strength of the association is similar to that of the classical cardiovascular risk factors [43]. Albumin in urine reflects widespread early vascular disease and abnormal endothelial function. Accordingly, our results showing a lower urine albumin associated with the SEAD suggest that this dietary pattern may have a role in preventing endothelial dysfunction, a key step in the pathogenesis of atheromatosis. Nevertheless, the magnitude of the association was small $(-1 \mathrm{mg} / \mathrm{l})$ when compared with the level required for a clinical diagnosis of albuminuria ( $>30 \mathrm{mg} / \mathrm{dl}$ ). As expected, results for the urine albumin-creatinine ratio were in line with those for urine albumin.

Blood pressure is a well established risk factor for CHD. The difference in blood pressure between the highest and lowest quartile of the SEAD score was $-1.6 \mathrm{~mm} \mathrm{Hg}$. Although the magnitude of the association is small, it may be important at the population level and is similar to the effect of interventions based on counseling and education to improve hygiene and dietary habits in the general population [44]. Moreover, the association between the SEAD score and systolic blood pressure is comparable to that of other healthy dietary patterns like the Mediterranean diet [36]. Our results are biologically plausible, since the SEAD is rich in foods that have been shown to reduce blood pressure, such as legumes and vegetables, and dairy products [45]. In addition, better adherence to the SEAD was not associated with higher sodium intake (Table 1).

Of note is that although the associations between the SEAD and CRP, triglycerides, urine albumin, and blood pressure are small, the cumulative effects of SEAD on all of these biomarkers (and in turn on CHD) are likely to be greater than those expected from its association with a single factor because of the well known synergistic effect of cardiovascular risk factors.

Differences between men and women in results for certain biomarkers (e.g., insulin and insulin resistance) should be replicated in future research, because they were not part of hypotheses formulated $a$ priori; moreover, some sex-differences are to be expected just by chance because we have performed a large number of analyses.

Lastly, in a previous study we observed that the effect of the SEAD in reducing the risk of non-fatal AMI was close to that observed for the Mediterranean diet [4]. In fact, there is a certain overlap between the SEAD and the Mediterranean diet because the Pearson correlation between the SEAD score and the Trichopoulou index was 0.23 . It is indeed reassuring to know that the associations between the SEAD score and markers of CHD risk are comparable to those for the Mediterranean diet, although the latter diet was also linked to lower serum creatinine and BMI

\subsection{Study limitations and strengths}

Our study has some limitations. The main one is the crosssectional design which does not allow for causal inference. Furthermore, although the diet was measured with a validated dietary history, some recall error is possible. Also, diet was measured only once, which may have underestimated the study associations (regression dilution bias). An additional limitation is that both the SEAD score and the Mediterranean diet index were calculated using population-specific cut-off points (the population median), so that they only serve to categorize study participants according to the degree of adherence to each dietary pattern; however, they do not represent an absolute measure of the adherence to the SEAD or the Mediterranean diet in any population, and cannot be used to compare adherence to these diets between populations. Moreover, only one measurement was made of CHD biomarkers, blood pressure and anthropometry, which may have affected the results for biomarkers with the highest intraindividual variability, like triglycerides and urine albumin. Lastly, results were based on a variable number of individuals, which ranged from 10231 for BMI to 10073 for fibrinogen determination. This variation was mostly due to refusals in the physical examination and to problems in the manipulation and laboratory determinations in biological samples.

Among the study strengths are the large sample size which is representative of the adult population of an entire country. Furthermore, the laboratory tests were performed in a central laboratory, which reduces their variability. Lastly, the analyses were controlled for many potential confounding factors.

\section{Conclusion}

This study suggests mediators of the effect of the SEAD in the prevention of myocardial infarction, since SEAD is associated with 
a lower concentration of markers of inflammation, and with reduced triglycerides, insulin, insulin resistance, and systolic blood pressure.

\section{Author contributions}

All authors contributed to study concept and design. PG-C and AO conducted the data analysis. PG-C and FR-A drafted the manuscript. All authors contributed to interpretation of results and critically reviewed the manuscript for important intellectual content. PG-C and FR-A had primary responsibility for the final content. All authors read and approved the final manuscript. Conflict of interest: None of the authors had a personal of financial conflict of interest.

\section{Funding}

Data for this work have been taken from the ENRICA study, which was funded by Sanofi-Aventis. Specific funding for this work was obtained from 'Fondo de Investigación Sanitaria (FIS)' grants PI09-1626 and PI11/01379 and from the 'Cátedra UAM de Epidemiología y Control del Riesgo Cardiovascular'.

\section{Appendix A. Supplementary data}

Supplementary data related to this article can be found at http:// dx.doi.org/10.1016/j.atherosclerosis.2012.11.035.

\section{References}

[1] Varela G, Moreiras O, Ansón R. Consumo de Alimentos en Galicia-La Dieta Atlántica [Food consumption in Galicia-the Atlantic diet]. Madrid, Spain: Fundación Española de Nutrición; 2004.

[2] IV Reunión internacional de la alimentación y la nutrición en el siglo XXI. Dieta Atlántica. La obesidad como problema de Salud Pública. [Fourth International Meeting of diet and nutrition in the XXI century. Atlantic diet. Obesity as a Public Health Problem.]. http://www.fen.org.es/imgPublicaciones/ 7720085444.pdf, [accessed 09.05.12].

[3] Willett WC, Sacks F, Trichopoulou A, et al. Mediterranean diet pyramid: a cultural model for healthy eating. Am J Clin Nutr 1995;61(6 Suppl.):1402S-6S.

[4] Oliveira A, Lopes C, Rodriguez-Artalejo F. Adherence to the southern European Atlantic Diet and occurrence of nonfatal acute myocardial infarction. Am J Clin Nutr 2010;92(1):211-7.

[5] Rodriguez-Artalejo F, Graciani A, Guallar-Castillon P, et al. Rationale and methods of the study on nutrition and cardiovascular risk in Spain (ENRICA). Rev Esp Cardiol 2011;64(10):876-82.

[6] Aromaa A, Koponen P, Tafforeau J, Vermeire C. Evaluation of health interview surveys and health examination surveys in the European union. Eur J Public Health 2003;13(3 Suppl.):67-72.

[7] EPIC group of Spain. Relative validity and reproducibility of a diet history questionnaire in Spain. I. Foods. EPIC group of Spain. European prospective investigation into cancer and nutrition. Int J Epidemiol 1997;1(26 Suppl. ):S91-9.

[8] EPIC group of Spain. Relative validity and reproducibility of a diet history questionnaire in Spain. II. Nutrients. EPIC group of Spain. European prospective investigation into cancer and nutrition. Int J Epidemiol 1997;1(26 Suppl. ):S100-9.

[9] EPIC group of Spain. Relative validity and reproducibility of a diet history questionnaire in Spain. III. Biochemical markers. EPIC group of Spain. European prospective investigation into cancer and nutrition. Int J Epidemiol 1997; 1(26 Suppl.):S110-7.

[10] Jiménez Cruz A, Cervera Ral P, Bacardí Gascón M. Tabla de composición de alimentos. 1st ed. Barcelona: Wander-Sandoz Nutrition; 1990.

[11] Farrán A, Zamora R, Cervera P. Centre d'Ensenyament Superior de Nutritió i Dietetica (CESNID). Tablas de composición de alimentos del CESNID. Barcelona: McGraw-Hill/Internamericana de España, Universitat de Barcelona; 2004.

[12] Moreiras O, Carvajal A, Cabrera L, Cuadrado C. Tablas de composición de alimentos. 11th ed. Madrid: Pirámide; 2007.

[13] Guallar-Castillon P, Balboa-Castillo T, López-Garcia E, Leon-Munoz LM. Contenido de cafeína, selenio, yodo, ácidos grasos trans y ácidos grasos omega-3 y omega-6 en alimentos de consumo frecuente en España. [Content of caffeine, selenium, iodine, trans fatty acids, amega- 3 and omega- 6 fatty acids in foods commonly consumed in Spain. Madrid: Departamento de Medicina Preventiva y Salud Pública. Universidad Autónoma de Madrid; 2011.
[14] Ortega Anta RM, López Sobaler AM, Carvajales PA, Requejo Marcos AM. Programa DIAL [1.15]; 2007.

[15] Friedewald WT, Levy RI, Fredrickson DS. Estimation of the concentration of low-density lipoprotein cholesterol in plasma, without use of the preparative ultracentrifuge. Clin Chem 1972;18(6):499-502.

[16] Matthews DR, Hosker JP, Rudenski AS, Naylor BA, Treacher DF, Turner RC. Homeostasis model assessment: insulin resistance and beta-cell function from fasting plasma glucose and insulin concentrations in man. Diabetologia 1985 28(7):412-9.

[17] Banegas JR, Rodriguez-Artalejo F, Ruilope LM, et al. Hypertension magnitude and management in the elderly population of Spain. J Hypertens 2002;20(11):2157-64.

[18] Gutierrez-Fisac JL, Guallar-Castillon P, Leon-Munoz LM, Graciani A, Banegas JR, Rodriguez-Artalejo F. Prevalence of general and abdominal obesity in the adult population of Spain, 2008-2010: the ENRICA study. Obes Rev 2012; 13(4):388-92.

[19] Pols MA, Peeters PH, Ocke MC, Slimani N, Bueno-de-Mesquita HB, Collette HJ Estimation of reproducibility and relative validity of the questions included in the EPIC physical activity questionnaire. Int J Epidemiol 1997;1(26 Suppl.):S181-9.

[20] Ainsworth BE, Haskell WL, Whitt MC, et al. Compendium of physical activities: an update of activity codes and MET intensities. Med Sci Sports Exerc 2000; 32(9 Suppl.):S498-504.

[21] Trichopoulou A, Kouris-Blazos A, Wahlqvist ML, et al. Diet and overall survival in elderly people. BMJ 1995;311(7018):1457-60.

[22] Trichopoulou A, Costacou T, Bamia C, Trichopoulos D. Adherence to a Mediterranean diet and survival in a Greek population. N Engl J Med 2003;348(26): 2599-608.

[23] Sayon-Orea C, Bes-Rastrollo M, Basterra-Gortari FJ, et al. Consumption of fried foods and weight gain in a Mediterranean cohort: the SUN project. Nutr Metab Cardiovasc Dis 2011. http://dx.doi.org/10.1016/j.numecd.2011.03.014.

[24] Hansson GK. Inflammation, atherosclerosis, and coronary artery disease. N Engl J Med 2005;352(16):1685-95.

[25] Casas JP, Shah T, Hingorani AD, Danesh J, Pepys MB. C-reactive protein and coronary heart disease: a critical review. J Intern Med 2008;264(4):295-314.

[26] Kaptoge S, Di AE, Lowe G, et al. C-reactive protein concentration and risk of coronary heart disease, stroke, and mortality: an individual participant metaanalysis. Lancet 2010;375(9709):132-40.

[27] Hemingway H, Philipson P, Chen R, et al. Evaluating the quality of research into a single prognostic biomarker: a systematic review and meta-analysis of 83 studies of C-reactive protein in stable coronary artery disease. PLoS Med 2010;7(6):e1000286.

[28] Wensley F, Gao P, Burgess $S$, et al. Association between $C$ reactive protein and coronary heart disease: mendelian randomisation analysis based on individual participant data. BMJ 2011;342:d548.

[29] Ridker PM, Danielson E, Fonseca FA, et al. Rosuvastatin to prevent vascular events in men and women with elevated C-reactive protein. N Engl J Med 2008;359(21):2195-207.

[30] Lopez-Garcia E, Schulze MB, Fung TT, et al. Major dietary patterns are related to plasma concentrations of markers of inflammation and endothelial dysfunction. Am J Clin Nutr 2004;80(4):1029-35.

[31] Estruch R, Martinez-Gonzalez MA, Corella D, et al. Effects of a Mediterraneanstyle diet on cardiovascular risk factors: a randomized trial. Ann Intern Med 2006;145(1):1-11.

[32] Calder PC, Ahluwalia N, Brouns F, et al. Dietary factors and low-grade inflammation in relation to overweight and obesity. Br J Nutr 2011;3(106 Suppl.):S5-78.

[33] Miller M, Stone NJ, Ballantyne C, et al. Triglycerides and cardiovascular disease: a scientific statement from the American heart association. Circulation 2011;123(20):2292-333.

[34] Sarwar N, Sandhu MS, Ricketts SL, et al. Triglyceride-mediated pathways and coronary disease: collaborative analysis of 101 studies. Lancet 2010; 375(9726):1634-9.

[35] Anderson JW, Konz EC. Obesity and disease management: effects of weight loss on comorbid conditions. Obes Res 2001;4(9 Suppl.):326S-34S.

[36] Kastorini CM, Milionis HJ, Esposito K, Giugliano D, Goudevenos JA Panagiotakos DB. The effect of Mediterranean diet on metabolic syndrome and its components: a meta-analysis of 50 studies and 534,906 individuals. J Am Coll Cardiol 2011;57(11):1299-313.

[37] Appel LJ, Sacks FM, Carey VJ, et al. Effects of protein, monounsaturated fat, and carbohydrate intake on blood pressure and serum lipids: results of the OmniHeart randomized trial. JAMA 2005;294(19):2455-64.

[38] Balk E, Chung M, Lichtenstein A, et al. Effects of Omega-3 fatty acids on cardiovascular risk factors and intermediate markers of cardiovascular disease. Evidence report/technology assessment No. 93 (prepared by TuftsNew England Medical Center Evidence-Based Practice Center under contract No. 290-02-0022). AHRQ publication No. 04-E010-2. Rockville, MD: Agency for Healthcare Research and Quality; 2004.

[39] Fung TT, Rimm EB, Spiegelman D, et al. Association between dietary patterns and plasma biomarkers of obesity and cardiovascular disease risk. Am J Clin Nutr 2001;73(1):61-7.

[40] Esposito K, Di PC, Maiorino MI, et al. Long-term effect of mediterranean-style diet and calorie restriction on biomarkers of longevity and oxidative stress in overweight men. Cardiol Res Pract 2011;2011:293916.

[41] Wolever TM, Bolognesi C. Prediction of glucose and insulin responses of normal subjects after consuming mixed meals varying in energy, protein, fat, carbohydrate and glycemic index. J Nutr 1996;126(11):2807-12. 
[42] Poudyal H, Panchal SK, Diwan V, Brown L. Omega-3 fatty acids and metabolic syndrome: effects and emerging mechanisms of action. Prog Lipid Res 2011; 50(4):372-87.

[43] Perkovic V, Verdon C, Ninomiya T, et al. The relationship between proteinuria and coronary risk: a systematic review and meta-analysis. PLoS Med 2008;5(10):e207.
[44] Ebrahim S, Taylor F, Ward K, Beswick A, Burke M, Davey SG. Multiple risk factor interventions for primary prevention of coronary heart disease. Cochrane Database Syst Rev 2011;1:CD001561.

[45] Sacks FM, Campos H. Dietary therapy in hypertension. N Engl J Med 2010; 362(22):2102-12 